\title{
Bacteriophages of Helicobacter pylori
}

\author{
Angela B. Muñoz ${ }^{1,2 *}$, Johanna Stepanian ${ }^{1}$, Alba Alicia Trespalacios ${ }^{1}$ and Filipa F. Vale2* \\ 1 Infectious Diseases Research Group, Microbiology Department, Sciences Faculty, Pontificia Universidad Javeriana, Bogotá, \\ Colombia, ${ }^{2}$ Host-Pathogen Interactions Unit, Research Institute for Medicines (iMed-ULisboa), Faculdade de Farmácia, \\ Universidade de Lisboa, Lisbon, Portugal
}

OPEN ACCESS

Edited by:

Eric Altermann,

AgResearch Ltd, New Zealand

Reviewed by:

Jeremy J. Barr

Monash University, Australia

Sarah O'Flaherty,

North Carolina State University,

United States

Junko Akada,

Oita University, Japan

*Correspondence:

Angela B. Muñoz

munozangela@javeriana.edu.co

Filipa F. Vale

f.vale@ff.ulisboa.pt;

vale.filipa@gmail.com

Specialty section:

This article was submitted to

Evolutionary and Genomic

Microbiology,

a section of the journal

Frontiers in Microbiology

Received: 04 April 2020

Accepted: 21 October 2020

Published: 12 November 2020

Citation:

Muñoz AB, Stepanian J, Trespalacios AA and Vale FF (2020)

Bacteriophages of Helicobacter pylori.

Front. Microbiol. 11:549084.

doi: 10.3389/fmicb.2020.549084
The bacterium Helicobacter pylori colonize the stomach in approximately half of the world's population. Infection with this bacterium is associated with gastritis, peptic ulcer, adenocarcinoma, and gastric mucosa-associated lymphoid tissue lymphoma. Besides being a pathogen with worldwide prevalence, H. pylori show increasingly high antibiotic resistance rates, making the development of new therapeutic strategies against this bacterium challenging. Furthermore, $\mathrm{H}$. pylori is a genetically diverse bacterium, which may be influenced by the presence of mobile genomic elements, including prophages. In this review, we analyze these issues and summarize various reports and findings related to phages and $\mathrm{H}$. pylori, discussing the relationship between the presence of these elements and the genomic diversity, virulence, and fitness of this bacterium. We also analyze the state of the knowledge on the potential utility of bacteriophages as a therapeutic strategy for $\mathrm{H}$. pylori.

Keywords: Helicobacter pylori, bacteriophage, phage therapy, prophage genetic diversity, phage-host interaction

\section{INTRODUCTION}

Helicobacter pylori is a spiral-shaped, microaerophilic, Gram-negative, pathogenic bacterium that colonizes and persists in the human stomach. H. pylori infection is considered the most frequent chronic bacterial infection worldwide (Camilo et al., 2017). All individuals infected with H. pylori present with chronic gastritis, while $20 \%$ develop peptic ulcer and less than $1 \%$ develop adenocarcinoma or mucosa-associated lymphoid tissue (MALT)-type gastric lymphoma. Further, H. pylori infection is recognized as the leading risk factor for the development of gastric cancer (Polk and Peek, 2010). Numerous factors have been described as responsible for the progression of the infection to more severe diseases: although these factors may be inherent to the host (Figueiredo et al., 2017; Miftahussurur et al., 2017), several $\mathrm{H}$. pylori virulence factors have also been associated with malignancy. The most frequently associated are the Cag pathogenicity island (cagPAI) and the VacA vacuolating cytotoxin (Denic et al., 2020).

CagPAI is a genetic locus of $40 \mathrm{~kb}$, comprising 31 genes that encode a type IV secretion system (T4SS). The T4SS enables the injection of bacterial components, such as the CagA oncoprotein, into host gastric epithelial cells (Soluri et al., 2020). VacA is a toxin secreted by $H$. pylori that inserts into host cell membranes to form chloride-sensitive channels and disrupt endolysosomal trafficking, causing an accumulation of dysfunctional lysosomes and autophagosomes (Denic et al., 2020). Most H. pylori strains isolated have the vacA gene. However, differences in the alleles of the signal (s) and middle (m) regions of this gene are responsible for differing levels of cytotoxicity (Oktem-Okullu et al., 2020). 
In addition to the virulence of $H$. pylori, another critical challenge for clinicians has been to find an optimal treatment that takes into account the high levels of resistance of $H$. pylori to antibiotics (Camargo et al., 2014; Talebi Bezmin Abadi, 2017). $H$. pylori cure rates using antibiotic treatment have been reported to be as low as 57\% (Dos Santos and Carvalho, 2015). The minimum acceptable rate for a first attempt based treatment is 90\% (Nijevitch et al., 2014; Jones et al., 2017). Current treatments are based on the use of antibiotics combined with a proton pump inhibitor (PPI) (Malfertheiner et al., 2017). The PPI is used to increase intragastric $\mathrm{pH}$ because, at an acidic $\mathrm{pH}, H$. pylori transforms into its antibiotic-resistant coccoid form (Ierardi et al., 2019). Furthermore, acidic $\mathrm{pH}$ decreases the antimicrobial activity and half-life of antibiotics (Otero et al., 2018).

The increasing rates of $H$. pylori antibiotic resistance have necessitated the development of new therapeutic strategies (Vítor and Vale, 2011). An emerging alternative treatment for antibiotic-resistant bacterial infections is phage-therapy, which uses bacteriophages, also known as phages, to eliminate a bacterial population (Lin D. M. et al., 2017). The resurgence of this therapy has been due mainly to studies showing that phages are highly specific and easy to isolate (Loc-Carrillo and Abedon, 2011); moreover, phage therapy has demonstrated effectiveness in treating various infections, even curing chronic infections (Abedon, 2019). Despite the benefits of this therapy, its use for the treatment of $H$. pylori infection is a distant goal, considering that the understanding of $H$. pylori phage biology is still in its infancy.

Phages, which are viral particles that infect bacteria, may be lytic, lysogenic, or pseudo-lysogenic. Lytic phages recognize bacterial surfaces and inject their nucleic acids into the host cell; then, they assemble, multiply, and finally disrupt the cell to release phage progeny that infect new bacterial cells (Sulakvelidze, 2005). In lysogenic phages, phage DNA integrates into the bacterial genome, forming prophages (also known as template phages). Prophages promote bacterial evolution via horizontal gene transfer and induce the transduction of several genes involved in the biological behaviors of the bacterium (Brüssow et al., 2004; Paterson et al., 2010; Touchon et al., 2016). Pseudo-lysogenic phages are present as episomes (i.e., the genetic material is not integrated into the bacterial genome) and postpone cell lysis in nutrientdepleted hosts (Uchiyama et al., 2013); both lytic and lysogenic phages, under certain conditions, may acquire episomal forms (Łoś and Wȩgrzyn, 2012).

Bacteriophages represent the absolute majority of all organisms in the biosphere (Hatfull and Hendrix, 2011). Among the various bacteriophages, the discovery of $H$. pylori prophages has been of particular importance in explaining this bacterium's tremendous genetic diversity. This review aims to collate and analyze relevant publications regarding phages related to $H$. pylori and to understand how these phages impact the diversity and virulence of this bacterium. Additionally, we summarize reports on lytic phages with activity against $H$. pylori.

\section{H. pylori Prophages}

The first observations of phage-like intracellular particles in preparations of $H$. pylori were made shortly after the discovery of this bacterium (Marshall et al., 1987; Goodwin et al., 1989). In the early 1990s, a lysogenic strain of H. pylori that produced phage particles spontaneously was described (Schmid et al., 1990). Three years later, the lytic cycle of this phage was reproduced. Negative stain electron microscopy revealed that phage heads of around 50 to $60 \mathrm{~nm}$ and the DNA length was estimated to be 22,000 bp (Heintschel Von Heinegg et al., 1993).

With recent advances in sequencing technologies, studies aiming at the discovery of phages are increasing. Since 2011, investigations focusing on the analysis of Helicobacter spp. genomes have been published that corroborate the presence of prophages in the bacterial genome and analyze their functions in this context (Lehours et al., 2011; Luo et al., 2012; Uchiyama et al., 2012, 2013, 2016; Vale et al., 2015, 2017; Secka et al., 2017; Vale and Lehours, 2018) (Table 1). These studies report that prophages are present in around $20 \%$ of $H$. pylori isolates. The first of these studies reported a prophage sequence in H. pylori isolated from a patient with MALT lymphoma. This prophage, named PhiHp33, was isolated from $H$. pylori strain B45 and could be induced by UV light. Genomic sequence analysis demonstrated that $H$. pylori strains from different regions carry full or partial prophage sequences. Analysis of integrase and holin gene sequences allowed differentiation of strains according to their geographical origin, generating results consistent with classification based on multi-locus sequence typing (MLST) (Lehours et al., 2011; Vale et al., 2015; Secka et al., 2017).

In 2012, the isolation of a new phage (1961P) from Taiwanese H. pylori strains was reported. This phage showed characteristics compatible with belonging to the family Podoviridae. Further, sequence analysis identified other similar prophages integrated into the genomes of different $H$. pylori strains that had previously been sequenced (Luo et al., 2012). Additionally, in the same year, the complete genome sequences of two $H$. pylori bacteriophages (KHP30 and KHP40) isolated from Japanese patients were reported. These prophages were obtained after spontaneous release of viral particles by $H$. pylori strains (Uchiyama et al., 2012). The KHP30 phage was characterized as spherical, with a lipid envelope. It was present in infected bacteria as an episome, indicating that it likely represents a new phage family (Uchiyama et al., 2013). Subsequently, the possibility of lysogeny of active KHP30-like phages in 174 Japanese $H$. pylori strains was examined because their genomes contain a putative integrase gene; one strain, NY40, was found to include a KHP30-like prophage sequence. In this strain, the attachment sites, att $L$ and $a t t R$, were almost the same place in the genome. Further, their sequences were detected previously by Lehours et al., suggesting an active parental KHP30-like phage integrated into the ancestral NY40 genome in a site-specific manner (Uchiyama et al., 2016).

Analysis of KHP30 has continued, with researchers investigating its effects on the behaviors of the host strain (NY43) and demonstrating differences between the characteristics of $H$. pylori strains infected with prophage and novel prophage-free derivative strains. A recent study indicated that the presence of bacteriophages induces genetic alterations in the host genome, leading to the continuous production of prophage-free derivatives that coexist in $H$. pylori microbial communities 
TABLE 1 | Main bacteriophages of $H$. pylori.

\begin{tabular}{|c|c|c|c|c|c|}
\hline Bacteriophage & Type & Family & $\begin{array}{l}\text { Genome } \\
\text { size (Kb) }\end{array}$ & Details & References \\
\hline $1961 P$ & Prophage & Podoviridae & 26.8 & $\begin{array}{l}\text { Accession number: NC_019512.1 Head: } 68-74 \text { nm Tail: } 23 \times \\
13.3 \mathrm{~nm}\end{array}$ & (Luo et al., 2012) \\
\hline $\begin{array}{l}\text { Campylobacter } \\
\text { piloridis strain }\end{array}$ & Prophage & No data & No data & Intracellular particles of $40 \mathrm{~nm}$ in diameter & (Marshall et al., 1987) \\
\hline $\begin{array}{l}\text { Campylobacter } \\
\text { pylori strain }\end{array}$ & Prophage & No data & No data & Intracellular particles of $85 \mathrm{~nm}$ in diameter & (Goodwin et al., 1989) \\
\hline De-M53-M & Prophages & No data & 28.1 & Prophage population: hpNEurope Accession number: KX119205 & (Vale et al., 2017) \\
\hline Fr-ANT170-U & Prophage & No data & 31.2 & Prophage population: hpAfrica1 Accession number: KX119201 & (Vale et al., 2017) \\
\hline Fr-B41-M & Prophage & No data & 29.4 & Prophage population: hpSWEurope Accession number: KX119190 & (Vale et al., 2017) \\
\hline Fr-B58-M & Prophage & No data & 22.6 & Prophage population: hpEastAsia Accession number: KX119193 & (Vale et al., 2017) \\
\hline Fr-G12-G & Prophage & No data & 28.6 & Prophage population: hpEastAsia Accession number: KX119194 & (Vale et al., 2017) \\
\hline Fr-GC43-A & Prophage & No data & 33.0 & Prophage population: hpEastAsia Accession number: KX119195 & (Vale et al., 2017) \\
\hline Fr-MEG235-U & Prophage & No data & 31.2 & Prophage population: hpAfrica1 Accession number: KX119200 & (Vale et al., 2017) \\
\hline HP1 & Prophage & Siphoviridae & 22 & Head:50-60 nm Tail:170 × 9.5 nm & $\begin{array}{l}\text { (Heintschel Von } \\
\text { Heinegg et al., 1993) }\end{array}$ \\
\hline KHP30 & Prophage & $\begin{array}{l}\text { Cannot be } \\
\text { classified / new } \\
\text { family }\end{array}$ & 26.2 & $\begin{array}{l}\text { Episome Accession number: NC_019928.1 Head: } 67-71 \text { nm } \\
\text { Without tail }\end{array}$ & $\begin{array}{l}\text { (Uchiyama et al., 2012, } \\
\text { 2013; Takeuchi et al., } \\
\text { 2018) }\end{array}$ \\
\hline KHP40 & Prophage & No data & 26.4 & KHP30-like Accession number: NC_019931.1 & (Uchiyama et al., 2012) \\
\hline PhiHp33 & Prophage & Siphoviridae & 24.6 & $\begin{array}{l}\text { Inducible by UV light Accession number: NC_016568 Head: } \\
\text { 55-70 nm Tail: } 92 \times 6 \text { nm }\end{array}$ & (Lehours et al., 2011) \\
\hline Pt-1293-U & Prophage & No data & 30.1 & Prophage population: hpAfrica1 Accession number: KX119202 & (Vale et al., 2017) \\
\hline Pt-1846-U & Prophage & No data & 28.0 & Prophage population: hpAfrica1 Accession number: KX119176 & (Vale et al., 2017) \\
\hline Pt-1918-U & Prophage & No data & 28.7 & Prophage population: hpSWEurope Accession number: KX119192 & (Vale et al., 2017) \\
\hline Pt-212-99R-U & Prophage & No data & 23.0 & Prophage population: hpAfrica1 Accession number: KX119193 & (Vale et al., 2017) \\
\hline Pt-228_99-G & Prophage & No data & 30.1 & Prophage population: hpAfrica1 Accession number: KX119175 & (Vale et al., 2017) \\
\hline Pt-4472-G & Prophage & No data & 27.6 & Prophage population: hpSWEurope Accession number: KX119190 & (Vale et al., 2017) \\
\hline Pt-4481-G & Prophage & No data & 25.4 & Prophage population: hpAfrica1 Accession number: KX119196 & (Vale et al., 2017) \\
\hline Pt-4497-U & Prophage & No data & 29.4 & Prophage population: hpSWEurope Accession number: KX119191 & (Vale et al., 2017) \\
\hline Pt-5322-G & Prophage & No data & 28.3 & Prophage population: hpAfrica1 Accession number: KX119198 & (Vale et al., 2017) \\
\hline Pt-5771-G & Prophage & No data & 29.8 & Prophage population: hpAfrica1 Accession number: KX119199 & (Vale et al., 2017) \\
\hline Pt-B89-G & Prophage & No data & 27.4 & Prophage population: hpAfrica1 Accession number: KX119203 & (Vale et al., 2017) \\
\hline Pt-B92-G & Prophage & No data & 30.5 & Prophage population: hpAfrica1 Accession number: KX119197 & (Vale et al., 2017) \\
\hline Sw-A626-G & Prophage & No data & 31 & Prophage population: hpNEurope Accession number: KX119177 & (Vale et al., 2017) \\
\hline Sw-577-G & Prophage & No data & 26.9 & Prophage population: hpNEurope Accession number: KX119204 & (Vale et al., 2017) \\
\hline UK-EN31-U & Prophage & No data & 30.5 & Prophage population: hpNEurope Accession number: KX119174 & (Vale et al., 2017) \\
\hline UK-EN32-U & Prophages & No data & 29.9 & Prophage population: hpNEurope Accession number: KX119206 & (Vale et al., 2017) \\
\hline$\phi$ HPE1 & Lytic & Podoviridae & No data & Titer: $10^{9}$ PFU/ml Head: $62 \mathrm{~nm}$ Short noncontractile tail: $12 \times 6 \mathrm{~nm}$ & $\begin{array}{l}\text { (Abdel-Haliem and } \\
\text { Askora, 2013) }\end{array}$ \\
\hline$\phi$ HPE2 & Lytic & Siphoviridae & No data & Titer: $10^{10}$ PFU/ml Head: 95 nm Tail: $180 \times 15$ nm & $\begin{array}{l}\text { (Abdel-Haliem and } \\
\text { Askora, 2013) }\end{array}$ \\
\hline Hр $\varphi$ & Lytic & No data & No data & $\begin{array}{l}\text { Used in synergy with lactoferricin and hydroxyapatite. Adsorption } \\
\text { rate: } 1.89 \times 109 \mathrm{~mL} / \mathrm{min} \text { Latent period: } 45 \text { min Burst size: } 80 \text { PFU }\end{array}$ & (Cuomo et al., 2020) \\
\hline $\begin{array}{l}\text { H. pylori strain } \\
\text { BAPOUI }\end{array}$ & Lytic & No data & No data & Obtained from human feces Head: $100 \mathrm{~nm}$ Without tail & (Vale et al., 2008) \\
\hline
\end{tabular}

and confer diversity in morphology, motility, viability, and pathogenicity. Further, this study reported that KHP30 prophage could specifically suppress CagA expression (Takeuchi et al., 2018). Another study conducted using an $H$. pylori strain isolated from an ethnic minority patient in China revealed the presence of a $32.5 \mathrm{~kb}$ prophage integrated into the genome and demonstrated that most of its genes (30/33) were the same as those of KHP30; however, in this case, the prophage was inserted between two putative virulence genes, oipA and $\operatorname{homB}$, which encode adherence factors that mediate interactions between H. pylori and the host microenvironment. The authors suggest that the presence of a prophage inserted in this region indicates that HomB and OipA may act as receptors for the phage (You et al., 2015). 
In addition to the characterization of $H$. pylori prophages, the relationship between the presence of prophages and bacterial genetic diversity has been widely discussed. H. pylori is a genetically diverse species. This diversity has been associated with the geographic origin of populations (Matta et al., 2017) and likely influenced by the presence of mobile genomic elements, such as prophages, among other factors (Vale and Lehours, 2018). Since 2015, Vale et al. have reported that $H$. pylori prophages may contribute to bacterial genetic diversity. Most observations indicated a phylogeographic agreement between phage and bacterial genes, suggesting a co-evolution model between the virus and its bacterial host. Nonetheless, some prophages were assigned to populations distinct from their host, while others exhibited recombination signs among populations (Yahara et al., 2019). The phylogeographic distribution of H. pylori prophages can be characterized by Bayesian clustering analysis, based on a typing scheme that includes the sequences of two prophage genes: integrase (which is responsible for the integration of the phage genome into the bacterial chromosome) and holin (which is involved in cell lysis during a lytic cycle). Four prophage populations have been described: hpAfrical, hpEastAsia, hpNEurope, and hpSWEurope, notably subdividing the European population (Vale et al., 2015). Recently, based on the whole-genome analysis of $\mathrm{H}$. pylori, two subpopulations of hpEurope were also observed (Thorell et al., 2017).

Available information on $H$. pylori prophage diversity indicates that prophages and bacteria share a complex evolutionary history (Vale et al., 2017) and that the bacterial genome has been widely modified, in diverse regions, via horizontal gene transfer (Takeuchi et al., 2018). A few studies have investigated the presence of phages in other $H$. pylori strains; for example, a study from 2016 reported the detection of a $31.7 \mathrm{~kb}$ prophage in an $\mathrm{H}$. pylori strain isolated from a Mexican patient with gastric cancer (Mucito-Varela et al., 2016). Further, Kumar et al. (2017) analyzed H. pylori strains from Kuwait and reported a prophage in a strain isolated from a patient with active chronic gastritis and focal intestinal metaplasia.

In silico analyses have revealed prophage orthologous genes in the genomes of bacterial strains with virulence genes such as cagA or vacA (Kyrillos et al., 2016). Reports suggest that prophages inserted in the $H$. pylori genome represent essential elements for the adaptation of this bacterium to hostile environments, because metabolic advantages or tolerance mechanisms that can be influenced by prophages may improve $H$. pylori competitiveness. Nevertheless, no specific prophage functions have, as yet, been recognized in $H$. pylori, and the roles of prophage in disease have rarely been recorded (Vale et al., 2017). Long-term colonization of the human stomach by $H$. pylori has allowed it to evolve together with its human host for more than 100,000 years (Moodley et al., 2012). Furthermore, because of frequent mutation and recombination events and horizontal gene transfer events, $H$. pylori is an extremely diverse bacterium. Specifically, H. pylori is naturally competent for transformation and highly competent in recombination, making the exchange of chromosomal DNA fragments between strains frequent and highly efficient (Fischer et al., 2020). Phages have generally been considered as actively involved in the processes of recombination and horizontal genetic exchange. In this context, a recent study presented a quantitative analysis of the described recombination events of $H$. pylori phage genes, revealing frequent recombination among phage core genes previously reported as less prone to recombination. This observation appears to reflect the co-evolutionary relationships of these phages with their hosts, revealing the evolutionary arms race that exists, either to contribute to phage escape from bacterial immunity or to protect hosts that produce defective phages. The high recombination rate in $H$. pylori phages suggests that they are among the most recombinogenic phages on earth (Yahara et al., 2019). To further advance knowledge of this topic, it is important to investigate the biological and genomic characteristics of $H$. pylori phages in detail. Likewise, valuable information may emerge from the continued search for phage in strains associated with different pathologies and from various geographical locations. Furthermore, important insights may be obtained through investigation of phage insertion sites and their roles in the bacterial genome, considering that prophages can act as gene reservoirs, which may benefit pathogens in ways that are just beginning to be determined.

\section{Lytic Bacteriophages of $\boldsymbol{H}$. pylori}

The rise of antibiotic resistance increased the interest in studying bacteriophages, particularly the lytic ones. Indeed, phage therapy has various potential advantages than antibiotic use because phages and phage lysins, are highly specific, affecting the target strain but not the microbiome (Brüssow, 2017). Further, phages only replicate at the infection site, and no secondary effects have been described (Matsuzaki et al., 2005). Although these findings indicate the potential to use phages to eradicate $H$. pylori, reports in this field are scarce.

At the time of this review, there were only three studies on lytic bacteriophages (Table 1): the first was published by Vale et al. (2008), who isolated one lytic phage from human feces. Not many characteristics of this phage are known. It was only reported that it is a phage without a tail and an approximate size of $100 \mathrm{~nm}$. The second study was published in 2013 by AbdelHaliem and Askora, who isolated and characterized two lytic phages (ФHPE1 and ФHPE2) from wastewater (Abdel-Haliem and Askora, 2013). These phages were classified, by electronic microscopy, as belonging to the Podoviridae and Siphoviridae families, respectively. The titers for ФHPE1 and ФHPE2 were $10^{9} \mathrm{PFU} / \mathrm{ml}$ and $10^{10} \mathrm{PFU} / \mathrm{ml}$, respectively. These studies did not offer data on the latent period, burst size, or antimicrobial potential of these phages.

A third recent study by Cuomo et al. (2020) describes a new therapeutic option based on using a lytic phage of $H$. pylori $(\mathrm{Hp} \varphi)$, isolated from gastric biopsies. The phage was tested alone and combined with lactoferrin (LA) and adsorbed on hydroxyapatite (HA) nanoparticles. The characterization of $\mathrm{Hp}$ $\varphi$ revealed that the adsorption rate was $1.89 \times 10^{9} \mathrm{~mL} / \mathrm{min}$, the latent period was $45 \mathrm{~min}$, and the burst size was only $80 \mathrm{PFU}$. These analyses showed that the use of the complex (Hp $\varphi+$ LF-HA) enhances the activity of $\mathrm{Hp} \varphi$ up to 4 times. The use of HA as a vehicle can improve the natural properties of both Нр $\varphi$ and LF because it protects the gastric acid environment. 
An important finding, considering that phages are often sensitive to extreme $\mathrm{pH}$ values such as those associated with stomach acidity (Da̧browska and Abedon, 2019).

The studies available to date have not addressed certain aspects important for defining phage- therapy. The genome sequences of the phages remain unavailable. Genomic analysis could determine whether the phage genome comprises genes involved in lysogenic events, encode toxins, or represent determinants of antimicrobial resistance, or whether they code for lytic cycle repressors, or site-specific integrases or recombinases (Fernández et al., 2019). Likewise, considering the specific defense mechanisms mounted by bacteria against bacteriophage infections, it is essential to address the possible resistance that H. pylori may develop against these phages (Hyman and Abedon, 2010). The study by Cuomo et al. (2020) does not define the minimum effective combined doses of $\mathrm{Hp} \varphi$ and LF-HA.

Additional to the use of lytic phages, the use of phage lysins and related bacteriolytic enzymes are also being considered in phage therapy (Fischetti, 2018). Many phages have polysaccharide depolymerases and lysins that recognize, bind, and degrade the polysaccharide compounds (Latka et al., 2017). The enzyme holin could also be used as a therapeutic alternative. This enzyme is involved in the holin-endolysin pathway responsible for the first steps of bacterial lysis, which begins when the holin forms micrometer-scale holes in the bacterial inner membrane, releasing active endolysin into the periplasm to degrade peptidoglycan (Cahill and Young, 2019). Studies have evaluated the effect of enzymes for the treatment of bacterial infections mainly caused by gram-negative bacteria, and have shown efficacy in reducing bacterial virulence (D'andrea et al., 2017; Lin H. et al., 2017; Majkowska-Skrobek et al., 2018; Solovieva et al., 2018). Considering the presence of prophages in $H$. pylori and the background in other bacterial models, the investigation of these kinds of enzymes in $H$. pylori is feasible.

\section{CONCLUSION}

The findings reviewed here show that $H$. pylori genetic diversity is influenced by prophages, which are frequently found in strains of this bacterium, represent a structured population, and are highly recombinogenic. The additional genetic diversity that phages

\section{REFERENCES}

Abdel-Haliem, M. E. F., and Askora, A. (2013). Isolation and characterization of bacteriophages of Helicobacter pylori isolated from Egypt. Future Virol. 8, 821-826. doi: $10.2217 /$ fvl.13.58

Abedon, S. T. (2019). Use of phage therapy to treat long-standing, persistent, or chronic bacterial infections. Adv. Drug Deliv. Rev. 145, 18-39. doi: 10.1016/j. addr.2018.06.018

Brüssow, H. (2017). Infection therapy: the problem of drug resistance - and possible solutions. Microb. Biotechnol. 10, 1041-1046. doi: 10.1111/1751-7915.12777

Brüssow, H., Canchaya, C., and Hardt, W. D. (2004). Phages and the evolution of bacterial pathogens: from genomic rearrangements to lysogenic conversion. Microbiol. Mol. Biol. Rev. 68, 560-602. doi: 10.1128/MMBR.68.3.560-602. 2004

Cahill, J., and Young, R. (2019). Phage lysis: multiple genes for multiple barriers. Adv. Virus Res. 103, 33-70. doi: 10.1016/bs.aivir.2018.09.003 may provide to $H$. pylori confers advantages to this bacterium in terms of persistence and colonization of different human populations. The study of $H$. pylori phages has gained importance considering the substantial challenges posed by infection with this bacterium, including low eradication rates and antibiotic resistance. Phages appear to be a promising approach for the design of future therapies. Advances in research to improve understanding of phage and $H$. pylori interactions are required, and studies investigating whether prophage genes belonging to the lysis cassette are useful for phage-therapy are warranted. Further, identification of more lytic phages of $H$. pylori would allow considering the phage-therapy as an alternative approach for eradicating $H$. pylori, which would undoubtedly mark a milestone in the history of applications of $H$. pylori phages.

\section{AUTHOR CONTRIBUTIONS}

AM, JS, AT, and FV conceived the review. AM and JS collected the information. AM and FV wrote the manuscript. All authors contributed to the manuscript revision, read, and approved the submitted version.

\section{FUNDING}

This work was supported by the following sources: AM is a recipient of a scholarship from the Centro de Estudios Interdisciplinarios Básicos y Aplicados (CEIBA Foundation), Colombia. AM, JS, and AT are recipients of a project grant (120380763025/2018) from the Departamento Administrativo de Ciencia, Tecnología e Innovación de Colombia (Colciencias) and a project grant (PPTA_7676) from Research Vice-Rectory, Pontificia Universidad Javeriana. FV is the recipient of a project grant (PTDC/BTM-SAL/28978/2017) from the Fundação para a Ciência e a Tecnologia (FCT).

\section{ACKNOWLEDGMENTS}

We thank the entities that financially supported the development of this work.

Camargo, M. C., García, A., Riquelme, A., Otero, W., Camargo, C. A., HernandezGarcía, T., et al. (2014). The problem of Helicobacter pylori resistance to antibiotics: a systematic review in Latin America. Am. J. Gastroenterol. 109, 485-495. doi: 10.1038/ajg.2014.24

Camilo, V., Sugiyama, T., and Touati, E. (2017). Pathogenesis of Helicobacter pylori infection. Helicobacter 22(Suppl. 1), e12405. doi: 10.1111/hel.12405

Cuomo, P., Papaianni, M., Fulgione, A., Guerra, F., Capparelli, R., and Medaglia, C. (2020). An innovative approach to control. Microorganisms 8:1214. doi: 10.3390/microorganisms 8081214

Dąbrowska, K., and Abedon, S. T. (2019). Pharmacologically aware phage therapy: pharmacodynamic and pharmacokinetic obstacles to phage antibacterial action in animal and human bodies. Microbiol. Mol. Biol. Rev. 83:e00012-19. doi: 10.1128/MMBR.00012-19

D’andrea, M. M., Marmo, P., Henrici De Angelis, L., Palmieri, M., Ciacci, N., Di Lallo, et al. (2017). $\varphi$ BO1E, a newly discovered lytic bacteriophage targeting carbapenemase-producing Klebsiella pneumoniae of the pandemic 
Clonal Group 258 clade II lineage. Sci. Rep. 7:2614. doi: 10.1038/s41598-01702788-9

Denic, M., Touati, E., and De Reuse, H. (2020). Review: pathogenesis of Helicobacter pylori infection. Helicobacter 25(Suppl. 1):e12736. doi: 10.1111/hel. 12736

Dos Santos, A. A., and Carvalho, A. A. (2015). Pharmacological therapy used in the elimination of Helicobacter pylori infection: a review. World J. Gastroenterol. 21, 139-154. doi: 10.3748/wjg.v21.i1.139

Fernández, L., Gutiérrez, D., García, P., and Rodríguez, A. (2019). The perfect bacteriophage for therapeutic applications-a quick guide. Antibiotics 8:126. doi: 10.3390/antibiotics 8030126

Figueiredo, C., Camargo, M. C., Leite, M., Fuentes-Pananá, E. M., Rabkin, C. S., and Machado, J. C. (2017). Pathogenesis of gastric cancer: genetics and molecular classification. Curr. Top. Microbiol. Immunol. 400, 277-304. doi: 10.1007/9783-319-50520-6_12

Fischer, W., Tegtmeyer, N., Stingl, K., and Backert, S. (2020). Four chromosomal type IV secretion systems in Helicobacter pylori: composition, structure and function. Front. Microbiol. 11:1592. doi: 10.3389/fmicb.2020.01592

Fischetti, V. A. (2018). Development of phage lysins as novel therapeutics: a historical perspective. Viruses 10:310. doi: 10.3390/v10060310

Goodwin, C. S., Armstrong, J. A., and Peters, M. (1989). "Microbiology of C. pylori," in Campylobacter pylori in Gastritis and Peptic Ulcer Disease, ed. D. Y. Graham (New York, NY: Igaku-Shoin Medical Publishers), 25-49.

Hatfull, G. F., and Hendrix, R. W. (2011). Bacteriophages and their genomes. Curr. Opin. Virol. 1, 298-303. doi: 10.1016/j.coviro.2011.06.009

Heintschel Von Heinegg, E., Nalik, H. P., and Schmid, E. N. (1993). Characterisation of a Helicobacter pylori phage (HP1). J. Med. Microbiol. 38, 245-249. doi: 10.1099/00222615-38-4-245

Hyman, P., and Abedon, S. T. (2010). Bacteriophage host range and bacterial resistance. Adv. Appl. Microbiol. 70, 217-248. doi: 10.1016/S0065-2164(10) 70007-1

Ierardi, E., Losurdo, G., Fortezza, R. F., Principi, M., Barone, M., and Leo, A. D. (2019). Optimizing proton pump inhibitors in Helicobacter pylori treatment: old and new tricks to improve effectiveness. World J. Gastroenterol. 25, 50975104. doi: 10.3748/wjg.v25.i34.5097

Jones, N. L., Koletzko, S., Goodman, K., Bontems, P., Cadranel, S., Casswall, T., et al. (2017). Joint ESPGHAN/NASPGHAN guidelines for the management of Helicobacter pylori in children and adolescents (Update 2016). J. Pediatr. Gastroenterol. Nutr. 64, 991-1003. doi: 10.1097/MPG.0000000000001594

Kumar, N., Albert, M. J., Al Abkal, H., Siddique, I., and Ahmed, N. (2017). What constitutes an Arabian Helicobacter pylori? Lessons from comparative genomics. Helicobacter 22:e12323. doi: 10.1111/hel.12323

Kyrillos, A., Arora, G., Murray, B., and Rosenwald, A. G. (2016). The presence of phage orthologous genes in Helicobacter pylori correlates with the presence of the virulence factors CagA and VacA. Helicobacter 21, 226-233. doi: 10.1111/ hel. 12282

Latka, A., Maciejewska, B., Majkowska-Skrobek, G., Briers, Y., and Drulis-Kawa, Z. (2017). Bacteriophage-encoded virion-associated enzymes to overcome the carbohydrate barriers during the infection process. Appl. Microbiol. Biotechnol. 101, 3103-3119. doi: 10.1007/s00253-017-8224-6

Lehours, P., Vale, F. F., Bjursell, M. K., Melefors, O., Advani, R., Glavas, S., et al. (2011). Genome sequencing reveals a phage in Helicobacter pylori. mBio 2:e0239-11. doi: 10.1128/mBio.00239-11

Lin, D. M., Koskella, B., and Lin, H. C. (2017). Phage therapy: an alternative to antibiotics in the age of multi-drug resistance. World J. Gastrointest. Pharmacol. Ther. 8, 162-173. doi: 10.4292/wjgpt.v8.i3.162

Lin, H., Paff, M. L., Molineux, I. J., and Bull, J. J. (2017). Therapeutic application of phage capsule depolymerases against K1, K5, and K30 capsulated. Front. Microbiol. 8:2257. doi: 10.3389/fmicb.2017.02257

Loc-Carrillo, C., and Abedon, S. T. (2011). Pros and cons of phage therapy. Bacteriophage 1, 111-114. doi: 10.4161/bact.1.2.14590

Łoś, M., and Wẹgrzyn, G. (2012). Pseudolysogeny. Adv. Virus Res. 82, 339-349. doi: 10.1016/B978-0-12-394621-8.00019-4

Luo, C. H., Chiou, P. Y., Yang, C. Y., and Lin, N. T. (2012). Genome, integration, and transduction of a novel temperate phage of Helicobacter pylori. J. Virol. 86, 8781-8792. doi: 10.1128/JVI.00446-12
Majkowska-Skrobek, G., Latka, A., Berisio, R., Squeglia, F., Maciejewska, B., Briers, Y., et al. (2018). Phage-borne depolymerases decrease. Front. Microbiol. 9:2517. doi: $10.3389 /$ fmicb.2018.02517

Malfertheiner, P., Megraud, F., O’morain, C. A., Gisbert, J. P., Kuipers, E. J., Axon, A. T., et al. (2017). Management of Helicobacter pylori infection-the Maastricht V/florence consensus report. Gut 66, 6-30. doi: 10.1136/gutjnl-2016-312288

Marshall, B. J., Armstrong, J. A., Francis, G. J., Nokes, N. T., and Wee, S. H. (1987). Antibacterial action of bismuth in relation to Campylobacter pyloridis colonization and gastritis. Digestion 37(Suppl. 2), 16-30. doi: 10.1159/ 000199555

Matsuzaki, S., Rashel, M., Uchiyama, J., Sakurai, S., Ujihara, T., Kuroda, M., et al. (2005). Bacteriophage therapy: a revitalized therapy against bacterial infectious diseases. J. Infect. Chemother. 11, 211-219. doi: 10.1007/s10156-005-0408-9

Matta, A. J., Pazos, A. J., Bustamante-Rengifo, J. A., and Bravo, L. E. (2017). Genomic variability of Helicobacter pylori isolates of gastric regions from two Colombian populations. World J. Gastroenterol. 23, 800-809. doi: 10.3748/wjg. v23.i5.800

Miftahussurur, M., Yamaoka, Y., and Graham, D. Y. (2017). Helicobacter pylori as an oncogenic pathogen, revisited. Expert Rev. Mol. Med. 19:e4. doi: 10.1017/ erm.2017.4

Moodley, Y., Linz, B., Bond, R. P., Nieuwoudt, M., Soodyall, H., Schlebusch, C. M., et al. (2012). Age of the association between Helicobacter pylori and man. PLoS Pathog. 8:e1002693. doi: 10.1371/journal.ppat.1002693

Mucito-Varela, E., Castillo-Rojas, G., Cevallos, M. A., Lozano, L., Merino, E., López-Leal, G., et al. (2016). Complete genome sequence of Helicobacter pylori strain 7C isolated from a mexican patient with chronic gastritis. Genome Announc. 4:e01503-15. doi: 10.1128/genomeA.01503-15

Nijevitch, A. A., Idrisov, B., Akhmadeeva, E. N., and Graham, D. Y. (2014). Choosing optimal first-line Helicobacter pylori therapy: a view from a region with high rates of antibiotic resistance. Curr. Pharm. Des. 20, 4510-4516. doi: $10.2174 / 13816128113196660728$

Oktem-Okullu, S., Cekic-Kipritci, Z., Kilic, E., Seymen, N., Mansur-Ozen, N., Sezerman, U., et al. (2020). Analysis of correlation between the seven important Helicobacter pylori (H. pylori) virulence factors and drug resistance in patients with gastritis. Gastroenterol. Res. Pract. 2020:3956838. doi: 10.1155/2020/ 3956838

Otero, R. W., Gómez, Z. M., Otero, P. L., and Trespalacios, R. A. (2018). Helicobacter pylori: how do we treat it in 2018? Rev. Gastroenterol. Peru. 38, 54-63.

Paterson, S., Vogwill, T., Buckling, A., Benmayor, R., Spiers, A. J., Thomson, N. R., et al. (2010). Antagonistic co-evolution accelerates molecular evolution. Nature 464, 275-278. doi: 10.1038/nature08798

Polk, D. B., and Peek, R. M. (2010). Helicobacter pylori: gastric cancer and beyond. Nat. Rev. Cancer 10, 403-414. doi: 10.1038/nrc2857

Schmid, E. N., Von Recklinghausen, G., and Ansorg, R. (1990). Bacteriophages in Helicobacter (Campylobacter) pylori. J. Med. Microbiol. 32, 101-104. doi: 10.1099/00222615-32-2-101

Secka, O., Vale, F. F., Buissonnière, A., Thomas, J. E., Mégraud, F., and Lehours, P. (2017). Phylogeographic agreement between prophage and bacterial housekeeping genes in Helicobacter pylori strains from The Gambia. Helicobacter 22:e12394. doi: 10.1111/hel.12394

Solovieva, E. V., Myakinina, V. P., Kislichkina, A. A., Krasilnikova, V. M., Verevkin, V. V., Mochalov, V. V., et al. (2018). Comparative genome analysis of novel Podoviruses lytic for hypermucoviscous Klebsiella pneumoniae of K1, K2, and K57 capsular types. Virus Res. 243, 10-18. doi: 10.1016/j.virusres.2017. 09.026

Soluri, M. F., Puccio, S., Caredda, G., Edomi, P., D’elios, M. M., Cianchi, F., et al. (2020). Defining the Helicobacter pylori disease-specific antigenic repertoire. Front. Microbiol. 11:1551. doi: 10.3389/fmicb.2020.01551

Sulakvelidze, A. (2005). Phage therapy: an attractive option for dealing with antibiotic-resistant bacterial infections. Drug Discov. Today 10, 807-809. doi: 10.1016/S1359-6446(05)03441-0

Takeuchi, H., Kira, M., Konishi, S., Uchiyama, J., Matsuzaki, S., and Matsumura, Y. (2018). Polymorphisms in the Helicobacter pylori NY43 strain and its prophage-cured derivatives. Microbiology 164, 877-882. doi: 10.1099/mic.0. 000665 
Talebi Bezmin Abadi, A. (2017). Helicobacter pylori treatment: new perspectives using current experience. J. Glob. Antimicrob. Resist. 8, 123-130. doi: 10.1016/j. jgar.2016.11.008

Thorell, K., Yahara, K., Berthenet, E., Lawson, D. J., Mikhail, J., Kato, I., et al. (2017). Rapid evolution of distinct Helicobacter pylori subpopulations in the Americas. PLoS Genet. 13:e1006546. doi: 10.1371/journal.pgen.1006546

Touchon, M., Bernheim, A., and Rocha, E. P. (2016). Genetic and life-history traits associated with the distribution of prophages in bacteria. ISME J. 10, 2744-2754. doi: 10.1038/ismej.2016.47

Uchiyama, J., Takemura-Uchiyama, I., Kato, S., Takeuchi, H., Sakaguchi, Y., Ujihara, T., et al. (2016). Screening of KHP30-like prophages among Japanese Helicobacter pylori strains, and genetic analysis of a defective KHP30-like prophage sequence integrated in the genome of the H. pylori strain NY40. FEMS Microbiol. Lett. 363:fnw157. doi: 10.1093/femsle/fnw157

Uchiyama, J., Takeuchi, H., Kato, S., Gamoh, K., Takemura-Uchiyama, I., Ujihara, T., et al. (2013). Characterization of Helicobacter pylori bacteriophage KHP30. Appl. Environ. Microbiol. 79, 3176-3184. doi: 10.1128/AEM.035303512

Uchiyama, J., Takeuchi, H., Kato, S., Takemura-Uchiyama, I., Ujihara, T., Daibata, M., et al. (2012). Complete genome sequences of two Helicobacter pylori bacteriophages isolated from Japanese patients. J. Virol. 86, 11400-11401. doi: 10.1128/JVI.01767-12

Vale, F. F., and Lehours, P. (2018). Relating phage genomes to Helicobacter pylori population structure: general steps using whole-genome sequencing data. Int. J. Mol. Sci. 19:1831. doi: 10.3390/ijms19071831

Vale, F. F., Matos, A., Carvalho, P., and Vítor, J. (2008). Helicobacter pylori phage screening. Microsc. Microanal. 14, 150-151. doi: 10.1017/s1431927608089721
Vale, F. F., Nunes, A., Oleastro, M., Gomes, J. P., Sampaio, D. A., Rocha, R., et al. (2017). Genomic structure and insertion sites of Helicobacter pylori prophages from various geographical origins. Sci. Rep. 7:42471. doi: 10.1038/srep42471

Vale, F. F., Vadivelu, J., Oleastro, M., Breurec, S., Engstrand, L., Perets, T. T., et al. (2015). Dormant phages of Helicobacter pylori reveal distinct populations in Europe. Sci. Rep. 5:14333. doi: 10.1038/srep14333

Vítor, J. M., and Vale, F. F. (2011). Alternative therapies for Helicobacter pylori: probiotics and phytomedicine. FEMS Immunol. Med. Microbiol. 63, 153-164. doi: 10.1111/j.1574-695X.2011.00865.x

Yahara, K., Lehours, P., and Vale, F. F. (2019). Analysis of genetic recombination and the pan-genome of a highly recombinogenic bacteriophage species. Microb. Genom. 5:e000282. doi: 10.1099/mgen.0.000282

You, Y., He, L., Zhang, M., and Zhang, J. (2015). Comparative genomics of a Helicobacter pylori isolate from a Chinese Yunnan Naxi ethnic aborigine suggests high genetic divergence and phage insertion. PLoS One 10:e120659. doi: 10.1371/journal.pone.0120659

Conflict of Interest: The authors declare that the research was conducted in the absence of any commercial or financial relationships that could be construed as a potential conflict of interest.

Copyright (C) 2020 Muñoz, Stepanian, Trespalacios and Vale. This is an open-access article distributed under the terms of the Creative Commons Attribution License (CC BY). The use, distribution or reproduction in other forums is permitted, provided the original author(s) and the copyright owner(s) are credited and that the original publication in this journal is cited, in accordance with accepted academic practice. No use, distribution or reproduction is permitted which does not comply with these terms. 